\title{
Six-month field efficacy and safety of the combined treatment of dogs with Frontline Tri-Act ${ }^{\circledR}$ and NexGard Spectra ${ }^{\circledR}$
}

Jessica M. Abbate ${ }^{1}$, Ettore Napoli', Francesca Arfuso ${ }^{1}$, Gabriella Gaglio ${ }^{1}$, Salvatore Giannetto ${ }^{1}$, Lenaig Halos ${ }^{2}$, Frederic Beugnet ${ }^{2}$ and Emanuele Brianti ${ }^{1 *}$

\begin{abstract}
Background: Safety and efficacy of the combined monthly use of spot-on fipronil $6.76 \% \mathrm{w} / \mathrm{v} /$ permethrin $50.48 \%$ $\mathrm{W} / \mathrm{v}$ (Frontline Tri-Act ${ }^{\oplus}$ ) and chewable tablets of afoxolaner 1.9\% w/w / milbemycin oxime 0.4\% w/W (NexGard Spectra ${ }^{\oplus}$ ) in dogs was evaluated in a field study over a period of 6 months.

Methods: Forty-one healthy dogs living in highly endemic area for canine leishmaniosis and other canine vector borne diseases (VBD) were included in the study at the beginning of the Leishmania transmission season. Sixteen dogs were pet dogs living each in a single household; twenty-five dogs were hunting dogs living in three kennels. At inclusion, the dogs were ELISA (rapid test) negative for antibodies to Anaplasma, Borrelia, Ehrlichia, and for antigens of Dirofilaria. The dogs were also negative for blood microfilariae at the Knott's test, and no clinical or haematological abnormalities were observed. Of the included dogs, six hunting, apparently healthy, dogs were ELISA (rapid test) positive to Leishmania, and some were naturally infected by gastrointestinal nematodes (58.5\%) and/or infested by fleas (58.5\%) and ticks (9.8\%). All the included dogs were treated at Days 0, 28, 56, 84, 112 and 140, and followed-up for efficacy until the study end (Day 168).

Results: No adverse events related to the two products, nor skin reactions, general signs, or changes in the haematological profile, were observed during the study. At Day 14, anthelminthic efficacy was 100\% for Toxocara canis, Toxascaris leonina and Capillaria aerophila, while few hunting dogs were still shedding eggs of Trichuris vulpis (1/25 hunting dog) and Ancylostomatidae (9/25 hunting dogs). All pet dogs were nematode free at the end of the study. Hunting dogs were free of roundworms and whipworms. Twenty-four hours after the first treatment, 95.8\% of the ectoparasite infested dogs were free from fleas and ticks. Ectoparasites were significantly controlled during the 6-month study period, with 100\% efficacy on both fleas and ticks from Day 56 to Day 168. Blood and serum samples collected on Day 168 were tested for vector-borne pathogens using same methods of the inclusion and no new seroconversions or circulating blood microfilariae were observed.

Conclusions: Concomitant use of Frontline Tri-Act ${ }^{\circledR}$ and NexGard Spectra ${ }^{\circledR}$ in dogs for six months was well tolerated. The combination was effective in controlling fleas, ticks, gastro-intestinal nematodes, and neither new seroconversion to the tested vector-borne pathogens nor blood microfilariae were detected in treated dogs at the end of the study.
\end{abstract}

Keywords: Afoxolaner/milbemycin oxime, Canine vector-borne diseases, Ectoparasites, Efficacy, Fipronil/permethrin, Nematodes, Safety

\footnotetext{
* Correspondence: ebrianti@unime.it

${ }^{1}$ Dipartimento di Scienze Veterinarie, Università degli Studi di Messina, Polo

Universitario Annunziata, 98168 Messina, Italy

Full list of author information is available at the end of the article
}

(c) The Author(s). 2018 Open Access This article is distributed under the terms of the Creative Commons Attribution 4.0 International License (http://creativecommons.org/licenses/by/4.0/), which permits unrestricted use, distribution, and reproduction in any medium, provided you give appropriate credit to the original author(s) and the source, provide a link to the Creative Commons license, and indicate if changes were made. The Creative Commons Public Domain Dedication waiver (http://creativecommons.org/publicdomain/zero/1.0/) applies to the data made available in this article, unless otherwise stated. 


\section{Background}

Dogs are continuously exposed to parasitic infections and vector-borne diseases (VBD), with some of them being of zoonotic concern $[1,2]$. The risk is higher in animals living in communities (e.g. kennels or shelters) and/or with access to the outdoors [3]. Despite better attention to canine health and the use of highly effective anti-parasitic products, recent studies conducted throughout Europe have shown that intestinal nematode infections remain a common occurrence in dogs [4-6]. A recent survey conducted on 1390 owned dogs reported that more than a third of them were shedding eggs/cysts of endoparasites, i.e. nematodes, cestodes and/or protozoans [7]. The ratio of endoparasitic infections is higher if kennel dogs are included in the epidemiological surveys [8].

Ectoparasite infections, mainly caused by fleas and ticks, constantly challenge dogs [9]. Their role as vectors of many pathogens highlights the need for an efficacious year-round strategy of control $[10,11]$. Canine leishmaniosis (CanL), caused by Leishmania infantum, and canine dirofilariosis, due to Dirofilaria immitis or Dirofilaria repens, are among the most diffused and common VBD of dogs throughout Europe [12-15]. Several drivers are currently influencing the epidemiology of these diseases. Changes in vector presence, abundance and activity, as well as increased movements of animals from endemic areas into free territories and vice versa, seem to play key roles in this change in epidemiology [16]. As a result, the current distribution of CanL and canine heartworm disease (CHD) due to D. immitis is overlapping in several European countries, including Albania [17], Greece [18], France [2], Italy [3], Portugal $[13,14]$ and Spain [19]. This means that dogs living in these areas are at risk for both diseases during at least 4-6 months per year on average, which corresponds to the period of activity of the respective vectors (i.e. sand flies and mosquitoes).

Advances in research for the control of endo- and ectoparasites have resulted in the development of several highly effective veterinary products for the prevention of canine VBD. However, a single product that guarantees prevention against endoparasites, ectoparasites and canine VBD is not yet available. Therefore, the combined use of different drugs is likely to represent the only preventative solution to protect dogs under particular epidemiological settings [20].

Recently, two new antiparasitic products, namely Frontline Tri-Act ${ }^{ø}$ (Merial, now part of Boehringer Ingelheim), a topical solution combination of fipronil $6.76 \%$ w/v and permethrin 50.48\% w/v, and NexGard Spectra ${ }^{\circ}$ (Merial, now part of Boehringer Ingelheim), a chewable tablet containing afoxolaner $1.9 \% \mathrm{w} / \mathrm{w}$ and milbemycin oxime $0.4 \% \mathrm{w} / \mathrm{w}$, have been launched onto the veterinary market. The former is a spot-on formulation, effective for treatment and prevention of flea infestations, including Ctenocephalides felis and Ctenocephalides canis [21, 22] and ticks, including Dermacentor reticulatus, Rhipicephalus sanguineus (sensu lato) and Ixodes ricinus [23, 24]. The product has shown a repellent and insecticidal activity against mosquitoes and stable flies [25, 26], and against phlebotomine sand flies, the vectors of CanL, under laboratory conditions [27]. Moreover, the efficacy in preventing CanL in a cohort of naturally exposed dogs has been recently demonstrated in a hyperendemic area of Greece [18]. NexGard Spectra ${ }^{\circledR}$ is a systemic insecticidal and acaricidal product in a chewable formulation licensed for treatment and prevention of ectoparasite infestations (fleas and ticks), and treatment of gastrointestinal nematodes [7]. This product, due to the presence of milbemycin oxime, is also effective for the prevention of CHD [28].

The concomitant use of these two products could represent a reliable solution for a comprehensive protection against both endo- and ectoparasites, including the prevention of CanL and CHD. Currently, no information on their concomitant administration is available in literature. Therefore, the aim of the present study was to assess the safety and the efficacy of the monthly concurrent treatments with Frontline Tri-Act ${ }^{\circledR}$ and NexGard Spectra ${ }^{\oplus}$ in dogs for a period of six months.

\section{Methods \\ Study design}

The study was a non-controlled, un-blinded, field trial conducted on privately owned dogs. Animals were included in the study after collection of the owner written informed consent. The study was conducted in Sicily and Calabria regions (southern Italy) from May 2016 to January 2017.

Seventy-four dogs with a minimum body weight of 2 $\mathrm{kg}$ and older than 8 weeks were screened at the pre-inclusion visit on study day -7 (Day -7). Each animal was physically examined, and individual faecal and blood samples were collected for analyses (see Sample analyses section). Only dogs with satisfactory general health condition, not infected by agents of chronic debilitating diseases or VBD (i.e. anaplasmosis, borreliosis, ehrlichiosis and leishmaniosis), and without circulating microfilariae, were enrolled.

On Day 0, 41 dogs were included in the study and sampled again for faeces, checked for the presence of ectoparasites, and simultaneously treated with the two testing products at therapeutic doses and in compliance with manufacturer's instructions. Frontline Tri-Act ${ }^{\oplus}$ pipette was applied directly on animal's skin and divided in two approximately equal spots (i.e. at the base of the skull and between the blades of shoulders). NexGard 
Spectra $^{\circ}$ was administered to dogs initially by offering the chew for spontaneous ingestion or by putting it directly into the mouth, if the dog had not eaten the drug spontaneously. After treatment, each dog was observed for $2 \mathrm{~h}$ in order to detect any side effects (e.g. ptyalism, vomiting or skin reactions). All enrolled animals remained with their owners and kept as per normal routine for the entire study. The owners were instructed to assess the animal's health status daily and to notify any adverse event or behaviour abnormalities immediately.

After initial Day 0 treatment, the dogs were followed-up on Days 1, 14, 28, 56, 84, 112, 140 and 168, and were retreated with the two testing products every 28 days $( \pm 2)$ after clinical check and sampling (Table 1$)$. At each visit the dogs were clinically examined by evaluation of body temperature, body weight, nutritional status, respiratory, cardiovascular and gastrointestinal systems, and checked for tick and flea presence by thumbing and combing the fur for $\sim 3 \mathrm{~min}$. Individual faecal samples were collected and screened for gastrointestinal parasites using copromicroscopical analyses at each visit. Blood samples were collected from each dog on Days -7, 28, 84 and 168.

\section{Sample analyses}

Faecal samples were processed with Baermann-Wetzel technique [29] for the detection of broncho-pulmonary larvae and by a modified McMaster technique with a cut-off of 15 eggs per gram (epg) [30-33].

Blood was collected from a peripheral vein (jugular or cephalic) using a standard technique and stored in 2.5 $\mathrm{ml}$ anticoagulant ( $\mathrm{K}_{3}$ EDTA) tube and in $2.5 \mathrm{ml}$ cloth activator tube. A complete cells blood count $(\mathrm{CBC})$, including red blood cells (RBC), haemoglobin (HGB), haematocrit (HCT), white blood cells (WBC) and platelets (PLT), was performed on all blood samples using an automated haematology analyser (Benesphera ${ }^{* *} \mathrm{H} 32$
VET, Avantor Performance Materials Inc., Center Valley, PA, USA).

The presence of circulating microfilariae was assessed using a modified Knott's test [34] on Days -7 and 168 . Observed microfilariae were identified to species level using morphometric criteria [34].

Sera samples collected on Days -7 and 168 were tested by rapid ELISA assays for $L$. infantum using the Canine Leishmania Antibody Test Kit produced by IDEXX ${ }^{\circ}$ (IDEXX laboratories, Westbrook, ME, USA), and for Anaplasma spp., Borrelia spp., Ehrlichia spp., and D. immitis using SNAP $^{\circ}$ 4Dx Plus (IDEXX laboratories, Westbrook, ME, USA) following the producer's recommendations.

\section{Safety assessments}

Data on clinical parameters (body temperature, body weight, nutritional status, respiratory, cardiovascular and gastrointestinal systems) and $\mathrm{CBC}$ collected during clinical examinations and from analyses were compared to the data collected at the pre-inclusion visit, which were considered as baseline values. Pre-treatment haematological blood parameters (Day -7) were compared with values obtained at Days 28, 84 and 168 by means of one-way analysis of variance (ANOVA) for repeated measures.

The same statistical analysis was performed in order to evaluate the effect of time on dog's body weight values. When significant differences were found, Bonferroni's post hoc comparison was applied. A $P$-value < 0.05 was considered statistically significant. The statistical analysis was performed using the software GraphPad Prism version 5.1 (GraphPad Software, San Diego, California, USA).

Data on local tolerance of the spot-on treatment were also collected and the application sites were particularly examined for changes of the hair coat and skin.

Table 1 Dates and scheduled operations

\begin{tabular}{|c|c|c|c|c|c|c|c|c|c|c|}
\hline Activity & $\begin{array}{l}\text { Pre-inclusion } \\
\text { (Day -7) }\end{array}$ & $\begin{array}{l}\text { Inclusion } \\
\text { (Day 0) }\end{array}$ & $\begin{array}{l}\text { Day } 1 \\
\text { visit }\end{array}$ & $\begin{array}{l}\text { Day } 14 \\
\text { visit }\end{array}$ & $\begin{array}{l}\text { Day } 28 \\
\text { visit }\end{array}$ & $\begin{array}{l}\text { Day } 56 \\
\text { visit }\end{array}$ & $\begin{array}{l}\text { Day } 84 \\
\text { visit }\end{array}$ & $\begin{array}{l}\text { Day } 112 \\
\text { visit }\end{array}$ & $\begin{array}{l}\text { Day } 140 \\
\text { visit }\end{array}$ & $\begin{array}{l}\text { Day } 168 \\
\text { visit }\end{array}$ \\
\hline Clinical examination & + & + & + & + & + & + & + & + & + & + \\
\hline CBC & + & & & & + & & + & & & + \\
\hline $\begin{array}{l}\text { Copromicroscopy } \\
\text { (McMaster + Baermann) }\end{array}$ & + & + & & + & + & + & + & + & + & + \\
\hline Blood microfilariae & + & & & & & & & & & + \\
\hline Ectoparasites & + & + & + & + & + & + & + & + & + & + \\
\hline Anaplasma spp. serology & + & & & & & & & & & + \\
\hline Ehrlichia canis serology & + & & & & & & & & & + \\
\hline Leishmania infantum serology & + & & & & & & & & & + \\
\hline $\begin{array}{l}\text { Treatment (Frontline } \\
\text { Tri-Act+NexGard Spectra) }\end{array}$ & & + & & & + & + & + & + & + & \\
\hline
\end{tabular}




\section{Efficacy assessments}

Efficacy against endo- and ectoparasites was evaluated in the animals that scored positive at the inclusion. The effect (curative or preventive) against ectoparasites was assessed $24 \mathrm{~h}$ after the initial treatment, at Day 14, and then monthly until Day 168. The efficacy is expressed as a percentage of flea or tick free dogs as no ectoparasite counts were performed.

Due to the poor correlation between the egg numbers and parasite infestation for nematodes in dogs, the number of infected dogs at each sampling time-point assessed the efficacy against gastrointestinal and respiratory nematodes. The percentage of nematode free dogs was calculated for each parasite species.

\section{Results}

\section{Enrolment}

Among the 74 dogs screened, 41 dogs, with a mean age of 3.6 years and a weight ranging from 3.4 to $32 \mathrm{~kg}$, fulfilled the inclusion criteria and were included in the study at Day 0 (Table 2). The 33 excluded dogs had abnormal haematological parameters or tested positive to CanL or other vector borne diseases (Table 3). Six of the included hunting dogs were, however, seropositive to Leishmania but did not show clinical signs or pathological alterations and, therefore, were kept included

Table 2 Characteristics of the 41 dogs included in the study

\begin{tabular}{ll}
\hline Variable & No. of dogs \\
\hline Age & 14 \\
$\leq 12$ months & 15 \\
$12-60$ months & 12 \\
$>60$ months & \\
Size & 4 \\
Small $(\leq 7 \mathrm{~kg})$ & 24 \\
Medium $(7-18 \mathrm{~kg})$ & 13 \\
Large $(>18 \mathrm{~kg})$ & \\
Hair coat & 28 \\
Short & 7 \\
Medium & 6 \\
Long & \\
Life style & 16 \\
Pet & 25 \\
Hunting & 22 \\
Sex & \\
Female & \\
Male & \\
Breed & \\
Cross-breed & 219 \\
\hline
\end{tabular}

Table 3 Clinical assessment and evaluation of the 74 dogs screened at the pre-inclusion visit

\begin{tabular}{ll}
\hline Leishmania infantum seropositive dogs & $25 / 74(33.8 \%)$ \\
Ehrlichia canis seropositive dogs & $2 / 74(2.7 \%)$ \\
Anaplasma spp. seropositive dogs & $1 / 74(1.4 \%)$ \\
Gastrointestinal parasite positive dogs & $29 / 74(39.2 \%)$ \\
Fleas positive dogs & $26 / 74(35.1 \%)$ \\
Ticks positive dogs & $4 / 74(5.4 \%)$ \\
Alterations of the haematological parameters & $19 / 74(25.7 \%)$ \\
Owners not complying with the study protocol & $2 / 74(2.7 \%)$ \\
\hline
\end{tabular}

because co-housed in the same pen with other enrolled dogs.

Of the 41 enrolled dogs, 16 were pet dogs living each in a single household, and 25 were hunting dogs living in three kennels (6 in kennel 1, 7 in kennel 2, and 12 in kennel 3). One dog was lost by the owner after Day 84, one hunting dog deceased as outcome of hierarchy aggression by another dog (after Day 112), two other dogs did not come for veterinary visit and sampling on Days 84, 112, and 140 because of owner's unavailability, but came back on Day 168. For statistical analysis, only complete dog cases at Day $168(n=37)$ were used.

\section{Safety}

Neither adverse events related to the two products, nor skin reactions or general signs were observed during the study. No change of clinical examination parameters (i.e. body temperature, nutritional status, heart rate and respiratory rate) was recorded. The mean body weight showed a non-significant slight increase from the baseline, i.e. from 16.1 to $17.3 \mathrm{~kg}(\Delta=1.22, P=0.949)$.

Mean values of haematological parameters were within physiological limits of the species throughout the study period. However, a statistical significant increase of HCT $\left(F_{(3,160)}=36.21, P<0.0001\right), \operatorname{HGB}\left(F_{(3,160)}=44.35, P<\right.$ $0.0001)$ and PLT $\left(F_{(3,160)}=3.08, P=0.029\right)$ compared to the baseline values was observed on Days 84 and 168 (Table 4).

\section{Efficacy assessments}

At Day 0, 24 dogs (58.5\%) were found infected with gastrointestinal nematodes, i.e. $18.8 \%(3 / 16)$ pet dogs and $84 \%(21 / 25)$ hunting dogs $\left(\chi^{2}=17.1137, d f=1, P<\right.$ $0.0001)$. At inclusion, six parasite species/taxa were identified, with Trichuris vulpis (20/41, 48.8\%) and Ancylostomatidae $(15 / 41,36.6 \%)$ as the most frequent species, followed by Capillaria aerophila (8/41, $19.5 \%)$, Toxascaris leonina (7/41, 17.1\%), Toxocara canis $(6 / 41,14.6 \%)$ and Dipylidium caninum (3/41, 7.3\%).

At Day 14 visit, no eggs of $C$. aerophila, T. canis and $T$. leonina were found at coproscopy, while some 
Table 4 Mean values \pm standard deviation $(M \pm S D)$ of haematological parameters recorded in dogs during the study. Dogs were treated with Frontline Tri-Act and Nexgard Spectra on study Day 0 and thereafter every 28 ( \pm 2 days) up to Day 140

\begin{tabular}{|c|c|c|c|c|c|c|}
\hline \multirow[t]{3}{*}{ Parameters } & \multirow[t]{3}{*}{$\mathrm{RR}^{\mathrm{a}}$} & \multicolumn{4}{|l|}{ Study days } & \multirow[t]{3}{*}{$P$-value } \\
\hline & & Day -7 & Day 28 & Day 84 & Day 168 & \\
\hline & & $M \pm S D$ & $M \pm S D$ & $M \pm S D$ & $M \pm S D$ & \\
\hline RBC & $5.5-8.5 \times 10^{6} / \mu l$ & $6.8 \pm 0.9$ & $7.0 \pm 0.8$ & $7.2 \pm 0.7$ & $7.1 \pm 0.4$ & 0.12 \\
\hline WBC & $6-17 \times 10^{3} / \mu \mathrm{l}$ & $12.9 \pm 2.9$ & $12.0 \pm 2.5$ & $12.1 \pm 2.3$ & $11.9 \pm 12.6$ & 0.07 \\
\hline HCT & $39-56 \%$ & $42.2 \pm 6.2$ & $43.3 \pm 4.8$ & $46.2 \pm 4.4^{*}$ & $52.4 \pm 4.2^{*}$ & $<0.001$ \\
\hline HGB & $11-19 \mathrm{~g} / \mathrm{dl}$ & $14.3 \pm 2.2$ & $14.42 \pm 1.5$ & $14.9 \pm 1.4$ & $18.3 \pm 2.2^{*}$ & $<0.001$ \\
\hline PLT & $117-460 \times 10^{3} / \mu \mathrm{l}$ & $231.6 \pm 84.1$ & $233.6 \pm 75.3$ & $244.1 \pm 96.7$ & $284.8 \pm 108.2^{*}$ & $<0.05$ \\
\hline
\end{tabular}

Abbreviations: RBC Red blood cells, WBC white blood cells, HCT haematocrit, HGB haemoglobin, PLT platelets count

*Statistically significant different vs Day -7

${ }^{a}$ Reference range [36]

hunting dogs were still shedding eggs of T. vulpis $(1 / 25)$ and Ancylostomatidae (9/25). All pet dogs were found nematode free from Day 14 to Day 168. Except for the Ancylostomatidae, all the hunting dogs were nematode free from Day 112 assessment up to the end of the study (Table 5). None of the enrolled dogs tested positive at the Baermann-Wetzel technique neither at the pre-inclusion nor throughout the study period.

On Day 0 visits the percentage of dogs infested by fleas was $58.5 \%$ (3/16 pet dogs and $21 / 25$ hunting dogs; $\left.X^{2}=17.1137, d f=1, P<0.0001\right)$. On Day $1,40 / 41$ $(97.6 \%)$ of the dogs were flea-free and none of them was found infested by fleas on the following scheduled controls, except on Day 28 when seven hunting dogs (28\%) scored flea positive (Table 6).

On Day 0, tick infestation was observed in 1/16 (6.2\%) pet dogs and 3/25 (12\%) of the hunting kennel dogs; 24 $\mathrm{h}$ post-treatment the pet dog was still infested by ticks, while none of the animals scored positive for ticks in the other follow-ups (Table 6).

At inclusion and at Day 168, none of the enrolled dogs scored positive for Anaplasma spp., Borrelia spp., Ehrlichia spp. and D. immitis using the SNAP ${ }^{\circ} 4$ Dx Plus test.
No microfilariae were detected in blood samples, and all dogs scored ELISA (rapid test) negative to L. infantum antibodies with the exception of the six that were already positive at the inclusion.

\section{Discussion}

This study demonstrates how the concurrent use of Frontline Tri-Act ${ }^{\circ}$ and Nexgard Spectra ${ }^{\circ}$ in dogs for six months is effective and well tolerated. These findings are largely in line with what has been previously observed with the single use of both products under laboratory and field conditions [7, 18, 22, 24, 35].

Haematological parameters remained within the reference ranges [36], with a significant increase of $\mathrm{HCT}$, HGB and PLT observed on Days 84 and 168. This could be attributable to a general improvement of health conditions in treated dogs as they were dewormed and freed from ectoparasites. Also, it could be the result of increased physical activities [37], as the majority of these animals were hunting dogs and the last part of the study overlapped with the hunting season.

The species of gastrointestinal nematodes identified in the present field trial match with those reported in other surveys conducted throughout Europe [7]. The overall

Table 5 Number and percentage of infested dogs examined on pre- and post-treatment days

\begin{tabular}{|c|c|c|c|c|c|c|}
\hline \multirow{2}{*}{$\begin{array}{l}\text { Study } \\
\text { days }\end{array}$} & \multicolumn{6}{|c|}{ Number of positive dogs per endoparasite species (\%) } \\
\hline & Trichuris vulpis & Ancylostomatidae & Capillaria aerophila & Toxocara canis & Toxascaris leonina & Dipylidium caninum $^{a}$ \\
\hline Day 0 & 20/41 (48.8) & 15/41 (36.6) & $8 / 41(19.5)$ & 6/41 (14.6) & $7 / 41(17.1)$ & $3 / 41(7.3)$ \\
\hline Day 14 & $1 / 41(2.4)$ & 9/41 (22.0) & $0 / 41(0)$ & 0/41 (0) & 0/41 (0) & $0 / 41(0)$ \\
\hline Day 28 & 2/41 (4.9) & 15/41 (36.6) & $4 / 41(9.8)$ & $0 / 41(0)$ & 0/41 (0) & $1 / 41(2.4)$ \\
\hline Day 56 & $1 / 41(2.4)$ & 15/41 (36.6) & $0 / 41(0)$ & $0 / 41(0)$ & 0/41 (0) & $0 / 41(0)$ \\
\hline Day 84 & $1 / 39(2.6)$ & $10 / 39(25.6)$ & $0 / 39(0)$ & $1 / 39(2.6)$ & 0/39 (0) & $0 / 39(0)$ \\
\hline Day 112 & 0/37 (0) & $12 / 37(32.4)$ & 0/37 (0) & $1 / 37(2.7)$ & 0/37 (0) & 0/37 (0) \\
\hline Day 140 & 0/37 (0) & $13 / 37(35.1)$ & 0/37 (0) & 0/37 (0) & 0/37 (0) & 0/37 (0) \\
\hline Day 168 & 0/37 (0) & 10/37 (27) & 0/37 (0) & 0/37 (0) & 0/37 (0) & 0/37 (0) \\
\hline
\end{tabular}

${ }^{\mathrm{a}}$ Dogs found infected with Dipylidium caninum were treated with praziquantel, since this tapeworm species is not targeted by the two products tested in the study 
Table 6 Number of infested dogs and percentages of ectoparasite free dogs in the scheduled follow-ups. Dogs were treated with Frontline Tri-Act and Nexgard Spectra on study Day 0 and thereafter every 28 ( \pm 2 days) up to Day 140

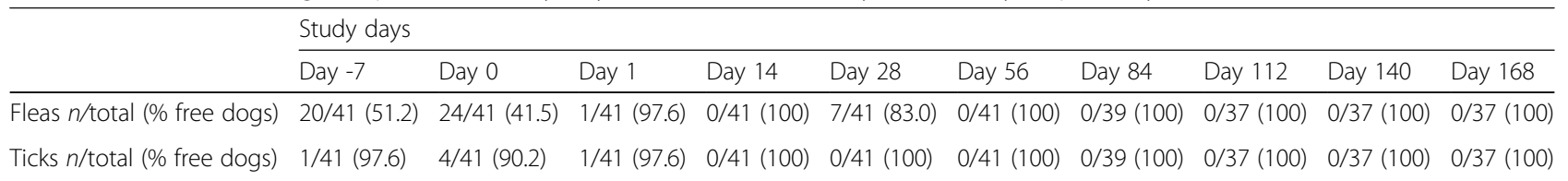

frequency of intestinal parasite infections reported here (from $14.6 \%$ to $48.8 \%$ according to species/taxa) was considerably high, especially in hunting dogs living in kennels with $84 \%$ of mixed infestation by endo- and ectoparasites. This underlines, once again how owned dogs may be significantly infected by intestinal parasites even if adult and apparently healthy pets [38]. All dogs included, whipworms and hookworms were the species with the highest frequencies (48.8 and 36.6\%, respectively). The presence of C. aerophila in $8 / 41$ (19.5\%) of the dogs, seven hunting dogs and one pet dog, is of particular interest. This trichuroid nematode infects the lungs of domestic (i.e. dogs and cats) and wild carnivores (e.g. foxes) and may represent a zoonotic hazard [39, 40]. Capillariosis in dogs and cats is increasingly diagnosed throughout Europe and the frequency of infection reported here is the highest ever reported in dogs so far [5, 41, 42], confirming how certain animal categories (e.g. hunting dogs) may be at great risk of infection.

The efficacy against intestinal parasites reported in the present study largely matches that observed previously in an extensive European multicentre field study [7]. At Day 112 and after, all dogs were free of whipworms, roundworms, and Capillaria. Conversely, the efficacy against hookworms was lower to what has previously been observed under both natural and experimental conditions $[7,43]$. It is important, however, to point out that all the dogs, which were continuously shedding Ancylostomatidae eggs, were hunting kennel dogs living with other untreated dogs in highly contaminated environment. Egg shedding would be related to re-infections, but also to regular coprophagy and passive migration of eggs from infected faeces. It is likely that re-infections could not be prevented due to the epidemiological situation in the three kennels. In kennel 1, the only hookworm infected dog became negative, in kennel 2, 4/7 infected dogs remained infected, and in kennel 3, from $8 / 12$ at the beginning, 6/10 dogs were infected at the end of the study. Indeed, the pre-patent period of Ancylostoma can be as short as 14 days, and their control in kennels may require regular anthelmintic treatments administered every 2 weeks until control is obtained, and then monthly administrations [38, 44].

In the present trial fleas and ticks were efficiently controlled in treated animals starting from 24 hours post-treatment when $97.6 \%$ of flea and tick pre-infested animals were cured. Tick infestations were totally prevented as no ticks were found on dogs treated from Day 14 up to Day 168. On Day 28, a few hunting dogs $(7 / 25)$ were found infested by fleas, but, interestingly, the majority of fleas collected during this visit were dead or moribund (data not shown). Thereafter, all dogs were flea-free. As already mentioned, the majority of dogs included in this trial were hunting dogs housed in kennels where other not included infested dogs were present, thus indicating a high regular exposure. Although acting with a different mode of action, both products here tested claim curative and preventative efficacy against ectoparasites of dogs; therefore, a synergistic action between them could not be ruled out and it may provide clues for the high efficacy profile here observed. However, it is important to note that the combined use of these products was primarily intended to provide a simultaneous protection against some VBD, especially CanL and CHD [7, 10, 24].

Despite this study was primarily designed to assess the safety and efficacy of the combined used of the two tested products, it also allowed the collection of supplementary data on the incidence of some vector-borne pathogens (VBP) in treated dogs. The study was indeed conducted in a hyper-endemic area for CanL, where a $54.6 \%$ incidence rate of infection has been reported in unprotected shelter dogs [45]. Most of the dogs screened at Day -7 were not enrolled in the study because they were already infected or diseased by L. infantum (see Table 3). The selected study area is also endemic for VBP transmitted by ticks, i.e. Anaplasma phagocytophilum, Babesia canis, Ehrlichia canis and Rickettsia conorii [46] and canine dirofilarioses, which have been reported in the same animal population $[47,48]$. In the present trial dogs were enrolled in May and completed the study in December after they had been exposed to one entire CanL transmission season. Despite the high risk of transmission, no negative treated dogs scored seropositive to L. infantum at study end; analogously, no seroconversion against other VBD causing pathogens (i.e. Anaplasma spp., Borrelia spp., Ehrlichia spp. and D. immitis) or blood microfilariae were detected in dogs at the end of the study. Tough the limitations in terms of sensibility of the sole use of serological tests for the diagnosis of some VBP such as L. infantum (e.g. exposed/infected dogs that may have not seroconvert yet), results 
of the current trial further corroborate what has been observed in a previous study specifically designed to assess the efficacy of the association permethrin/fipronil in reducing the risk of transmission in naturally exposed dogs living in a CanL hyper-endemic area [18].

\section{Conclusions}

The present study showed that the simultaneously administration of Frontline Tri-Act ${ }^{\circ}$ and Nexgard Spectra ${ }^{\circ}$ in dogs during a 6-month period is safe and provides a high efficacy in controlling ecto- and endoparasite infestations. In addition, neither new seroconversion to Anaplasma spp., Borrelia spp., Ehrlichia spp., L. infantum and D. immitis nor blood microfilariae were detected in treated dogs at the end of the study. By virtue of the repellent effect of the association fipronil/permethrin (Frontline Tri-Act ${ }^{\circ}$ ) against sand flies, and thanks to the efficacy of afoxolaner/milbemycin oxime (Nexgard Spec$\operatorname{tra}^{\circ}$ ) in preventing canine heartworm disease, the concomitant use of these products offers a broad spectrum of protection which may be regarded as a safe and effective prevention strategy for dogs, particularly those living in or travelling to geographical areas where the risk of CanL and CHD is overlapping.

\section{Abbreviations \\ CanL: Canine leishmaniosis; CBC: Cells blood count; CHD: Canine heartworm disease; ELISA: Enzyme-linked immunosorbent assay; HCT: Haematocrit; HGB: Haemoglobin; PLT: Platelets; RBC: Red blood cells; VBD: Vector-borne diseases; VBP: Vector-borne pathogens; WBC: White blood cells}

\section{Acknowledgements}

Manon Grieve, veterinary student at the National Veterinary School of Toulouse, France, was involved in the study as part of her training period at the Dipartimento di Scienze Veterianarie (UNIME) and is thanked for the help provided.

\section{Funding}

The study was partially funded by Merial, now part of Boehringer-Ingelheim Animal Health, 29 Avenue Tony Garnier, 69007 Lyon (cost of consumables and publication fees).

\section{Availability of data and materials}

All data generated or analysed during this study are included in this published article.

\section{Authors' contributions}

$E B, E N, F B$ and LH conceived and designed the study. JMA, EB, EN and GG carried out the field activities. JMA, EN, FA and GG carried out the laboratory work and statistical analyses. JMA and EN drafted the first version of the manuscript. EB, FA, GG, SG, FB and LH critical reviewed the manuscript. All authors read and approved the final manuscript.

\section{Ethics approval and consent to participate}

The protocol and the study design were approved by the Ethical Committee of the Department of Veterinary Sciences of the University of Messina (no. 003/16). Animals were included in the study only after the signature of an informed consent by the owner.

\section{Consent for publication}

Not applicable.

\section{Competing interests}

FB and LH are employees of Merial, now part of Boehringer-Ingelheim Animal Health, 29 Avenue Tony Garnier, 69007 Lyon. The other authors declare that they have no competing interests.

\section{Publisher's Note}

Springer Nature remains neutral with regard to jurisdictional claims in published maps and institutional affiliations.

\section{Author details}

${ }^{1}$ Dipartimento di Scienze Veterinarie, Università degli Studi di Messina, Polo Universitario Annunziata, 98168 Messina, Italy. ${ }^{2}$ Boehringer-Ingelheim Animal Health, 29 Av Tony Garnier, Lyon, France.

Received: 24 May 2018 Accepted: 15 June 2018

Published online: 16 July 2018

References

1. Day MJ. One health: the importance of companion animal vector-borne diseases. Parasit Vectors. 2011:4:49.

2. Baneth G, Thamsborg SM, Otranto D, Guillotx J, Blagax R, Deplazes P, et al. Major parasitic zoonoses associated with dogs and cats in Europe. J Comp Pathol. 2016;155:S54-74.

3. Otranto D, Dantas-Torres F. Canine and feline vector-borne diseases in Italy: current situation and perspectives. Parasit Vectors. 2010;3:2.

4. Grandemange E, Claerebout E, Genchi C, Franc M. Field evaluation of the efficacy and the safety of a combination of oxantel/pyrantel/praziquantel in the treatment of naturally acquired gastrointestinal nematode and/or cestode infestations in dogs in Europe. Vet Parasitol. 2007;145:94-9.

5. Riggio F, Mannella R, Ariti G, Perrucci S. Intestinal and lung parasites in owned dogs and cats from central Italy. Vet Parasitol. 2013;193:78-84.

6. Neves D, Lobo L, Simões PB, Cardoso L. Frequency of intestinal parasites in pet dogs from an urban area (Greater Oporto, northern Portugal). Vet Parasitol. 2014;200:295-8

7. Rehbein S, Knaus M, Mallouk Y, Breiltgens T, Brianti E, Capári B, et al. Efficacy against nematode infections and safety of afoxolaner plus milbemycin oxime chewable tablets in domestic dogs under field conditions in Europe. Parasitol Res. 2017;116:259-69.

8. Traversa D, Di Cesare A, Simonato G, Cassini R, Merola C, Diakou A, et al. Zoonotic intestinal parasites and vector-borne pathogens in Italian shelter and kennel dogs. Comp Immunol Microbiol Infect Dis. 2017;51:69-75.

9. Thomas JE, Staubus L, Goolsby JL, Reichard MV. Ectoparasites of free-roaming domestic cats in the central United States. Vet Parasitol. 2016;228:17-22.

10. Cardoso L. Fipronil and permethrin combination: A novel ectoparasiticide for dogs. Parasit Vectors. 2015;8:53.

11. ESCCAP. GL3: Control of Ectoparasites in Dogs and Cats. In: ESCCAP Guidelines. ESCCAP 2018. https://www.esccap.org/uploads/docs/gm7zb43y_ 0720 ESCCAP Guideline GL3 update v6.pdf. Accessed Mar 2018.

12. Trotz-Williams $L A$, Trees AJ. Systematic review of the distribution of the major vector-borne parasitic infections in dogs and cats in Europe. Vet Rec. 2003;152:97-105.

13. Maia C, Coimbra M, Ramos C, Cristóvão JM, Cardoso L, Campino L. Serological investigation of Leishmania infantum, Dirofilaria immitis and Angiostrongylus vasorum in dogs from southern Portugal. Parasit Vectors. 2015:8:152.

14. Maia C, Altet L, Serrano L, Cristóvão JM, Tabar MD, Francino O, et al. Molecular detection of Leishmania infantum, filariae and Wolbachia spp. in dogs from southern Portugal. Parasit Vectors. 2016;9:170.

15. Genchi C, Kramer L. Subcutaneous dirofilariosis (Dirofilaria repens): an infection spreading throughout the old world. Parasit Vectors. 2017;10:517.

16. Pantchev N, Schnyder M, Vrhovec MG, Schaper R, Tsachev I. Current surveys of the seroprevalence of Borrelia burgdorferi, Ehrlichia canis, Anaplasma phagocytophilum, Leishmania infantum, Babesia canis, Angiostrongylus vasorum and Dirofilaria immitis in dogs in Bulgaria. Parasitol Res. 2015;114: S117-30.

17. Hamel D, Shukullari E, Rapti D, Silaghi C, Pfister K, Rehbein S. Parasites and vector-borne pathogens in client-owned dogs in Albania. Blood pathogens and seroprevalences of parasitic and other infectious agents. Parasitol Res. 2016;115:489-99.

18. Papadopoulos E, Angelou A, Diakou A, Halos L, Beugnet F. Five-month serological monitoring to assess the effectiveness of permethrin/fipronil 
(Frontline Tri-Act ${ }^{\oplus}$ ) spot-on in reducing the transmission of Leishmania infantum in dogs. Vet Parasitol Reg Stud Rep. 2017;7:48-53.

19. Tabar MD, Altet L, Martínez V, Roura X. Wolbachia, filariae and Leishmania coinfection in dogs from a Mediterranean area. J Small Anim Pract. 2013;54:174-8.

20. Beugnet F, Franc M. Insecticide and acaricide molecules and/or combinations to prevent pet infestation by ectoparasites. Trends Parasitol. 2012;28:267-79

21. Beugnet F, Soll M, Bouhsira E, Franc M. Sustained speed of kill and repellency of a novel combination of fipronil and permethrin against Ctenocephalides canis flea infestations in dogs. Parasit Vectors. 2015;8:52.

22. Halos L, Fourie JJ, Frankhauser B, Beugnet F. Knock-down and speed of kill of a combination of fipronil and permethrin for the prevention of Ctenocephalides felis flea infestation in dogs. Parasit Vectors. 2016;9:57.

23. Jongejan F, De Vos C, Fourie JJ, Beugnet F. A novel combination of fipronil and permethrin (Frontline Tri-Act ${ }^{\oplus} /$ Frontect $^{\oplus}$ ) reduces risk of transmission of Babesia canis by Dermacentor reticulatus and of Ehrlichia canis by Rhipicephalus sanguineus ticks to dogs. Parasit Vectors. 2015;8:602.

24. Beugnet F, Halos L, Liebenberg J, Fourie J. Assessment of the prophylactic speed of kill of Frontline Tri-Act against ticks (Ixodes ricinus and Rhipicephalus sanquineus) on dogs. Parasite. 2016:23:2.

25. Fankhauser B, Dumont P, Hunter JS, McCall JW, Kaufmann C, Mathis A, et al. Repellent and insecticidal efficacy of a new combination of fipronil and permethrin against three mosquito species (Aedes albopictus, Aedes aegypti and Culex pipiens) on dogs. Parasit Vectors. 2015;8:64.

26. Fankhauser B, Irwin JP, Stone ML, Chester ST, Soll MD. Repellent and insecticidal efficacy of a new combination of fipronil and permethrin against stable flies (Stomoxys calcitrans). Parasit Vectors. 2015;8:61.

27. Dumont $P$, Fankhauser $B$, Bouhsira $E$, Lienard $E$, Jacquiet $P$, Beugnet $F$, et al. Repellent and insecticidal efficacy of a new combination of fipronil and permethrin against the main vector of canine leishmaniosis in Europe (Phlebotomus perniciosus). Parasit Vectors. 2015;8:49.

28. Tielemans $E$, Lebon W, Dumont P, Genchi M, Jeannin P, Larsen D. Efficacy of oral afoxolaner plus milbemycin oxime chewable (NexGard Spectra®, Merial) to prevent heartworm disease in dogs after inoculation with third stage larvae of Dirofilaria immitis. Liverpool: 25th International Conference of the World Association for the Advancement of Veterinary Parasitology (WAAVP); 2015.

29. Hendrix MC. Diagnostic veterinary parasitology. 2nd ed. St. Luis: Mosby; 1998.

30. MAFF. Manual of Veterinary Parasitological Laboratory Techniques, Fisheries and Food Reference Book. London: HMSO; 1986.

31. Bowman DD. Georgi's parasitology for veterinarians. Philadelphia: Saunders Company; 2009.

32. McGarry JW, Morgan ER. Identification of first-stage larvae of metastrongyles from dogs. Vet Rec. 2009;165:258-61.

33. Sloss MW, Zajac AM, Russel LK. Parassitologia clinica veterinaria. Edi Ermes: Milano; 2004

34. Magnis J, Lorentz S, Guardone L, Grimm F, Magi M, Naucke TJ, et al. Morphometric analyses of canine blood microfilariae isolated by the Knott's test enables Dirofilaria immitis and D. repens species-specific and Acanthocheilonema (syn. Dipetalonema) genus-specific diagnosis. Parasit Vectors. 2013;6:48.

35. Drag M, Saik J, Harriman J, Letendre L, Yoon S, Larsen D. Safety evaluation of orally administered afoxolaner and milbemycin oxime in eight-week-old dogs. J Vet Pharmacol Ther. 2017:40:447-53.

36. Weiss DJ, Wardrop KJ. Schalm's veterinary hematology. Philadelphia: WileyBlackwell; 2010

37. Piccione G, Casella S, Panzera M, Giannetto C, Fazio F. Effect of moderate treadmill exercise on some physiological parameters in untrained Beagle dogs. Exp Anim. 2012;6:511-5.

38. ESCCAP. GL1: Worm control in dogs and cats. In: ESCCAP Guidelines. ESCCAP. 2017. https://www.esccap.org/uploads/docs/0x0o7jda_ESCCAP_ Guideline_01_Third_Edition_July_2017.pdf. Accessed Jan 2018.

39. Lalosević D, Lalosević V, Klem I, Stanojev-Jovanović D, Pozio E. Pulmonary capillariasis miming bronchial carcinoma. Am J Trop Med Hyg. 2008;78:14-6.

40. Lalošević V, Lalošević D, Capo I, Simin V, Galfi A, Traversa D. High infection rate of zoonotic Eucoleus aerophilus infection in foxes from Serbia. Parasite. 2013;20:3.

41. Traversa D, Di Cesare A, Conboy G. Canine and feline cardiopulmonary parasitic nematodes in Europe: emerging and underestimated. Parasit Vectors. 2010;3:62.
42. Di Cesare A, Castagna G, Meloni S, Milillo P, Latrofa S, Otranto D, et al. Canine and feline infections by cardiopulmonary nematodes in central and southern Italy. Parasitol Res. 2011;109:S87-96.

43. Tielemans $E$, Lebon $W$, Dumont $P$, Taweethavonsawat $P$, Larsen $D$, Rehbein S. Efficacy of afoxolaner plus milbemycin oxime chewable tablets (NexGardSpectra ${ }^{\oplus}$, Merial) against adult Ancylostoma ceylanicum hookworm, in dogs. Vet Parasitol. 2017;238:87-9.

44. Companion Animal Parasite Council. www.capcvet.org. Accessed Mar 2018.

45. Brianti E, Gaglio G, Napoli E, Falsone L, Prudente C, Solari Basano F, et al. Efficacy of a slow-release imidacloprid (10\%)/flumethrin (4.5\%) collar for the prevention of canine leishmaniosis. Parasit Vectors. 2014;7:327.

46. Pennisi MG, Caprì A, Solano-Gallego L, Lombardo G, Torina A, Masucci M. Prevalence of antibodies against Rickettsia conorii, Babesia canis, Ehrlichia canis, and Anaplasma phagocytophilum antigens in dogs from the Stretto di Messina area (Italy). Ticks Tick Borne Dis. 2012;3:315-8.

47. Giannetto S, Poglayen G, Gaglio G, Brianti E. Prevalence and epidemiologica aspects of microfilaraemia in dogs in Sicily. In: 1st European Dirofilaria days: Zagreb, Croatia; 2007.

48. Brianti E, Gaglio G, Napoli E, Giannetto S, Dantas-Torres F, Bain O, et al. New insights into the ecology and biology of Acanthocheilonema reconditum (Grassi, 1889) causing canine subcutaneous filariosis. Parasitology. 2012;139: 530-6.

Ready to submit your research? Choose BMC and benefit from:

- fast, convenient online submission

- thorough peer review by experienced researchers in your field

- rapid publication on acceptance

- support for research data, including large and complex data types

- gold Open Access which fosters wider collaboration and increased citations

- maximum visibility for your research: over $100 \mathrm{M}$ website views per year

At BMC, research is always in progress.

Learn more biomedcentral.com/submissions 